\title{
Is the Anatomical Type of the Arcus Aorta an Effective Factor for the Success of Endovascular Therapy?
}

\author{
(1) Murat Çabalar ${ }^{1}$, (1) Nihat Şengeze ${ }^{2}$, (1) Alper Eren ${ }^{3}$, (1) Yusuf İnanç ${ }^{4}$, (1) Semih Giray ${ }^{4}$ \\ ${ }^{1}$ University of Health Sciences Turkey, Başakşehir Çam and Sakura City Hospital, Clinic of Neurology, İstanbul, \\ Turkey \\ ${ }^{2}$ Süleyman Demirel University Faculty of Medicine Hospital, Department of Neurology, Isparta, Turkey \\ ${ }^{3}$ Ataturk University Faculty of Medicine Hospital, Department of Neurology, Erzurum, Turkey \\ ${ }^{4}$ Gaziantep University Şahinbey Research and Practice Hospital, Clinic of Neurology, Gaziantep, Turkey
}

\section{What is known on this subject?}

Contrary to popular belief, anatomical differences in aortic arch structure are not rare. Knowing the anatomical features of this region before surgery and interventional procedures is very valuable in terms of being a road map to the operator. Namely, this different anatomic feature can cause technical difficulty and secondary ischemic problems caused by loss of time for the surgical or interventional procedure to be performed. As it is known, endovascular treatment, class I, level of evidence A, is recommended as a life-saving method recommended in appropriate patients with acute ischemic stroke. While modified-thrombolysis-incerebral-infarction ( $\mathrm{mTICl}$ ) $2 \mathrm{~b}$ and above for reperfusion in endovascular treatment is considered as a technical success, it is predicted to be TICI 3 for clinical success. The patient received intravenous recombinant tissue plasminogen activator before the procedure, the time to start the procedure/the duration of the procedure, the location/structure of the clot, the patient's age/comorbid condition, the material/technique used, the number of procedures, and the operator's experience are also very important for success, which is important. In addition, the anatomical feature of the aortic arch may be another factor affecting this success.

\section{What this study adds?}

In this study, we aimed to investigate the effect of aortic arch structure on the endovascular treatment procedure in patients with acute ischemic stroke and to discuss the clinical outcomes. 


\section{ABSTRACT}

Objective: This study aimed to investigate the relationship between the aortic arch structure classification and the success of endovascular reperfusion therapy in acute ischemic stroke (AIS).

Material and Methods: Between January 2018 and December 2018, 207 patients, who were brought to the Stroke Center of Gaziantep University, Şahinbey Research and Practice Hospital due to AIS and who underwent endovascular therapy, were analyzed retrospectively. The demographic features of patients, aortic arch classification, and modified-thrombolysis-in-cerebral-infarction $(\mathrm{mTICl})$ scores used for reperfusion in endovascular therapy were evaluated. Findings were statistically analyzed $(p<0.05)$.

Results: A total of 207 patients underwent endovascular procedures with the mean age was $64.4 \pm 13$ years, wherein 69 (33.3\%) had type 1 aortic arch, 99 (47.8\%) had type 2 aortic arch, and 39 (18.8\%) patients had type 3 aortic arch, whereas 47 (22.7\%) patients had a bovine arch. TICI $2 \mathrm{~b}$ and above recanalization were achieved in 188 (90.8\%) patients after endovascular therapy. At the end of the third month, good clinical outcomes were observed as modified Rankin scale of 0-2 in 78 (37.7\%) patients, whereas 61 (29.5\%) patients had mortality. The prognosis was worse in patients with type 3 aortic arch structure $(p=0.016)$.

Conclusion: Our study revealed that complex aortic arch structure had no negative effect on the success of endovascular therapy. However, the prognosis was poor at the end of the third month in patients with complex aortic arch structures.

Keywords: Aortic arch, endovascular therapy, mechanical thrombectomy, mRS, mTICI

\section{Introduction}

Contrary to popular belief, anatomical differences in the aortic arch structure are not rare. Knowing the anatomical features of this region before surgery and interventional procedures is very valuable in the road map of the operator (1). Different anatomic features can cause technical difficulty and secondary ischemic problems due to the time consumed for the surgical or interventional procedure. Class I endovascular treatment with a level of evidence A is recommended as a life-saving method for appropriate patients with acute ischemic stroke (AIS) (2), whereas modified-thrombolysis-in-cerebral-infarction ( $\mathrm{mTICl}$ ) 2b and above for endovascular reperfusion treatment is considered as a technical success and is predicted to be TICI 3 for clinical success $(3,4)$. Intravenous (IV) recombinant tissue plasminogen activator (r-tPA) administration before the procedure, the starting time or the duration of the procedure, the location/ structure of the clot, patient's age and comorbid conditions, the material/technique used, the number of procedures, and the surgeon's experience are also very important for success $(5,6)$. In addition, the anatomical feature of the aortic arch may be another factor that affects this success.

This study aimed to investigate the effect of the aortic arch structure on the endovascular treatment of patients with AIS and discuss its clinical outcomes.

\section{Material and Methods}

Between January 2018 and December 2018, 207 patients, who were admitted to the Stroke Center of Gaziantep University, Sahinbey Research and Practice Hospital due to AIS and who were treated with endovascular treatment (single-center digital angio device-Philips Brand Allura Xper FD 20 model), were retrospectively reviewed. In this study, 188 patients had anterior and 19 had posterior system large vessel occlusion. In addition to the demographic and clinical features of patients, the National Institutions of Health Stroke Scale (NIHSS) scores, Alberta Stroke Program Early Computed Tomography Score (ASPECT) scores, occlusion location, IV $r$-tPA administration before the procedure, intraarterial $r$-tPA administration during the procedure, symptom puncture/ recanalization times $(\mathrm{min})$, total intracranial procedure numbers, reperfusion mTICl scores, biochemistry-hemogram values, aortic arch types, and modified Rankin scale (mRS) scores in the third month, as well as mortality development, were analyzed.

The arch structure of all patients was determined with a 6-F pigtail catheter at the beginning of all procedures that are performed under general anesthesia. The arch was divided into three types according to the aortic anatomy that was based on the distance from the point where the brachiocephalic trunk originated from the aorta to the aortic arch apex. The distance in type 1 aortic arch was less than the left common carotid artery (CCA) diameter, type 2 was less than twice the left CCA diameter, and type 3 was more than twice the left CCA diameter. These arch types, which are important in performing endovascular procedures, are listed from simple to complex as type 1, type 2, and type 3 (Figure 1). The effect of bovine arch structure on the processes was also evaluated $(7,8)$.

Ethics committee approval was obtained from the Gaziantep University Clinical Research Ethics Committee dated 12.25.2019 and 2019/479. 


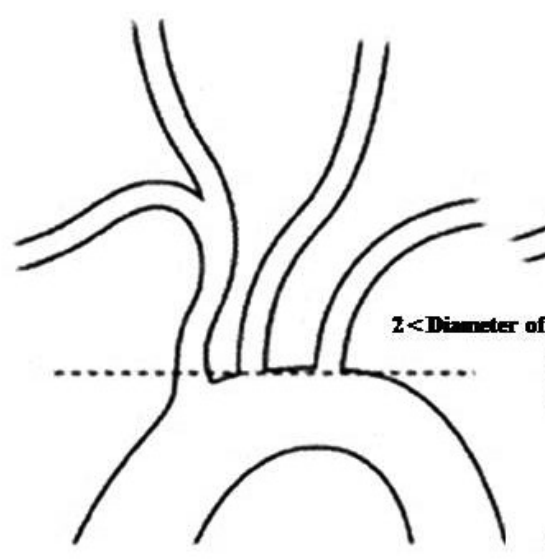

Type 1

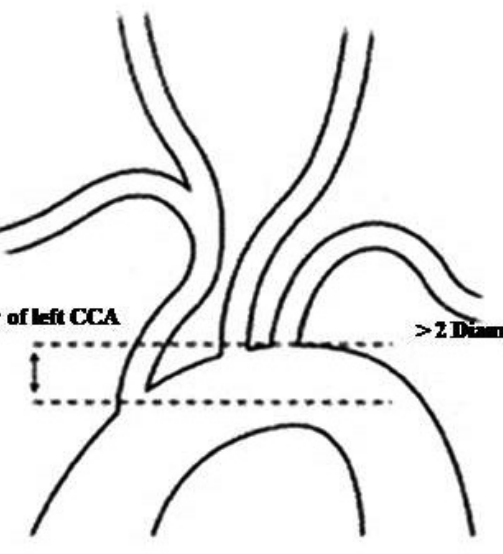

Type 2

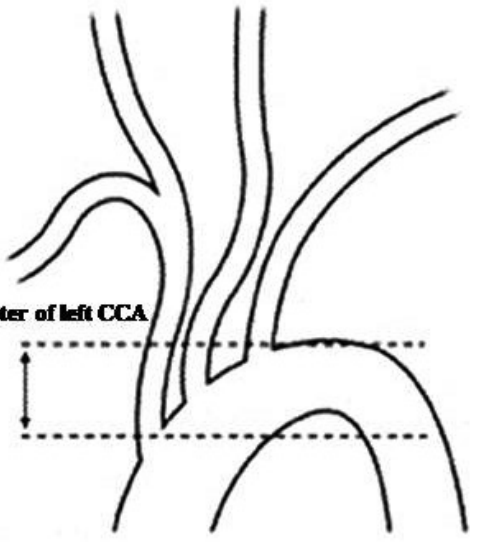

Type 3

Figure 1. Anatomical types of the arcus aorta

\section{Statistical Analysis}

Data were analyzed using the Statistical Package for the Social Sciences version 23 (Statistical Package for Social Sciences) package software program. Continuous variables were expressed in mean \pm standard deviation or median with interquartile range (25-75), and categorical variables in proportions. The distribution of quantitative data was analyzed using the Shapiro-Wilk test and all quantitative data was distributed non-parametrically. Non-normally distributed data were compared with non-parametric tests and normally distributed data with parametric tests. Results were analyzed using the Mann-Whitney $\mathrm{U}$ test and chi-squared test for nonparametric quantitative variables and categorical variables, respectively.

$P$ values of univariate analyses were adjusted for multiple testing with the false discovery rate method. Regression results were expressed in odds ratios and respective 95\% confidence intervals.

\section{Results}

A total of 207 patients underwent endovascular procedures with a mean age of $64.4 \pm 13$ years. The NIHSS score was calculated as median at 15 (12-19) (percentile 25$75)$ and the ASPECT score at first arrival was calculated as median at $9(8,9,10)$. The IV r-tPA was administered to 36 (17.4\%) patients before endovascular treatment. Great vessel occlusion was detected in 145 (70\%) patients. Type 1 arch was found in 69 (33.3\%) patients, whereas 99 (47.8\%) had type 2 arch and 39 (18.8\%) had type 3 arch. The bovine arch was seen in $47(22.7 \%)$ patients. $\mathrm{TICl} 2 \mathrm{~b}$ and above recanalization were achieved in 188 (90.8\%) patients after endovascular treatment. At the end of the third month, good clinical outcomes were observed as mRS 0-2 in 78 (37.7\%) patients, whereas 61 (29.5\%) had mortality. The aortic arch structures of patients were divided into two groups as type 1 and type 2/type 3 and compared to the demographic data, which revealed that the arch structure deteriorated with increasing age $(p=0.001)$. Decreased hemoglobin values were inversely proportional to age attracted attention. No statistically significant difference was found between the other data (Table 1). Demographic data were compared according to types 1 and 3 arch structures of patients, which revealed no statistically significant difference (Table 2). TICI $2 \mathrm{~b}$ and $\mathrm{TICl}$ 3 reperfusion results of types 1 and 3 arch structures were not statistically significant; however, type 3 arch structure decreased the $\mathrm{TICl} 2 \mathrm{~b}-3$ and above recanalization success $(p=0.99)$ (Table 3). The presence of bovine arch type did not make a significant difference for recalculation of $\mathrm{TICl} 2 \mathrm{~b}-3$ and above $(p=0.333)$. However, the recanalization rate in the first 45 min was lower in those with bovine arch type and left anterior system occlusion ( $p=0.021$ ) (Table 4$)$. Compared with the use of stent retriever of type 1 and types 2 and 3 arch structure, the use of stent retriever decreased in types 2 and 3 rather than type 1. The complex arch structure made the stent usage difficult, which was statistically significant $(p=0.017)$ (Table 5). The use of the arch structure types 2 and 3 rather large (6-F) Distal Access Catheter (DAC) was decreasing. Smaller (5-F) DAC was used in a complex arch structure $(p=0.021)$. The number of patients with good clinical outcomes between 0-2 mRS in the third month decreased in type 3 arch compared to type 1 . The complexity of the arch structure has a clinically poor prognosis $(p=0.016)$ (Table 6). 


\begin{tabular}{|c|c|c|c|}
\hline \multirow{3}{*}{ Demographic data } & \multicolumn{2}{|c|}{ Arcus arch type } & \multirow{3}{*}{ p value ${ }^{*}$} \\
\hline & Type 1 & Type 2 and 3 & \\
\hline & Median (25-75) & Median (25-75) & \\
\hline Age & $59(48-67)$ & $69(60-76)$ & 0.001 \\
\hline First NIHSS & $16(12-18)$ & $15(11-19)$ & 0.604 \\
\hline ASPECT score & $9(8-10)$ & $9(8-10)$ & 0.527 \\
\hline Symptom puncture time (min) & $200(120-260)$ & $200(120-245)$ & 0.768 \\
\hline Symptom recanalization time (min) & $260(195-310)$ & $263(195-315)$ & 0.839 \\
\hline Total intracranial procedures & $3(1-4)$ & $2(1-4)$ & 0.119 \\
\hline Third-month mRS & $3(2-5)$ & $3(2-6)$ & 0.426 \\
\hline Glucose & 138 (113-177) & 148 (119-212) & 0.161 \\
\hline Leukocyte & $10360(8470-12980)$ & $10280(8290-12700)$ & 0.866 \\
\hline Platelet & $258(209-310)$ & 264 (212-316) & 0.776 \\
\hline Hemoglobin & $13.9(12.2-15.1)$ & $13(11.8-14.3)$ & 0.014 \\
\hline RDW & $14.1(13.4-15)$ & $14.2(13.4-15.3)$ & 0.470 \\
\hline
\end{tabular}

\section{Table 2. Comparison of patients according to types 1 and 3 arch structures}

\begin{tabular}{|c|c|c|c|}
\hline \multirow{3}{*}{ Demographic data } & \multicolumn{2}{|c|}{ Arcus arch type } & \multirow{3}{*}{ p value* } \\
\hline & Type 1 & Type 3 & \\
\hline & Median (25-75) & Median (25-75) & \\
\hline Age & $59(48-67)$ & $71(62-77)$ & 0.001 \\
\hline First NIHSS & $16(12-18)$ & $16(14-20)$ & 0.414 \\
\hline ASPECT score & $9(8-10)$ & $9(8-10)$ & 0.252 \\
\hline Symptom puncture time (min) & $200(120-260)$ & $190(120-265)$ & 0.851 \\
\hline Symptom recanalization time (min) & $260(195-310)$ & $265(190-315)$ & 0.823 \\
\hline Total intracranial procedures & $3(1-4)$ & $2(1-5)$ & 0.702 \\
\hline Third-month mRS & $3(2-5)$ & $3(3-6)$ & 0.099 \\
\hline Glucose & 138 (113-177) & $146(117-200)$ & 0.823 \\
\hline Leukocyte & $10360(8470-12980)$ & $10600(8930-13110)$ & 0.531 \\
\hline Platelet & $258(209-310)$ & 237 (202-304) & 0.593 \\
\hline Hemoglobin & $13.9(12.2-15.1)$ & $13(11.9-14.3)$ & 0.106 \\
\hline RDW & $14.1(13.4-15)$ & $14(13.5-15.7)$ & 0.489 \\
\hline
\end{tabular}

\section{Discussion}

Dividing the anatomical differences of the aortic arch into two groups, as congenital and acquired, was possible. The first group had heterogeneous vascular anomalies, such as variations during the aortic arch development, and changes in the position of the arch and its branches that were accompanied by specific anatomical and clinical findings. In this group, six types of branching were found (9). The literature showed this type of aortic anomalies to be particularly associated with chromosomal defects, such as 22q11 deletion (10). Our study did not examine such abnormal branching patterns of the aortic arch. In the second group, anomalies were determined based on the distance from the point where 


\begin{tabular}{|c|c|c|c|}
\hline \multirow{2}{*}{$\begin{array}{l}\text { Successful recanalization } \\
\text { ( } \geq \text { mTICI 2b) }\end{array}$} & \multicolumn{2}{|c|}{ Arcus arch type } & \multirow{2}{*}{ p value ${ }^{*}$} \\
\hline & Type 1 N (\%) & Type 3 N (\%) & \\
\hline No & $4(40)$ & $6(60)$ & \multirow{3}{*}{0.99} \\
\hline Yes & $65(66.3)$ & $33(33.7)$ & \\
\hline Total & $69(63.9)$ & $39(36.1)$ & \\
\hline
\end{tabular}

\begin{tabular}{|c|c|c|c|}
\hline \multirow{2}{*}{$\begin{array}{l}\text { Recanalization in the first } 45 \\
\text { minutes }\end{array}$} & \multicolumn{2}{|c|}{ Bovine arch } & \multirow{2}{*}{ p value* } \\
\hline & $\begin{array}{l}\text { Right occlusion } \\
\mathrm{N}(\%)\end{array}$ & $\begin{array}{l}\text { Left occlusion } \\
\mathrm{N}(\%)\end{array}$ & \\
\hline Unsuccessful & $12(48)$ & $13(52)$ & \multirow{2}{*}{0.021} \\
\hline Successful & $17(81)$ & $4(19)$ & \\
\hline
\end{tabular}

\begin{tabular}{|c|c|c|c|}
\hline \multirow[t]{2}{*}{ Use of stent retriever } & \multicolumn{2}{|c|}{ Arcus arch type } & \multirow[t]{2}{*}{ p value* } \\
\hline & $\begin{array}{l}\text { Type } 1 \\
\mathrm{~N}(\%)\end{array}$ & $\begin{array}{l}\text { Type } 2 \text { and } 3 \\
\mathrm{~N}(\%)\end{array}$ & \\
\hline No & $16(22.5)$ & 55 (77.5) & \multirow[b]{2}{*}{0.017} \\
\hline Yes & $53(39)$ & 83 (61) & \\
\hline *Chi-square test & & & \\
\hline
\end{tabular}

\begin{tabular}{|c|c|c|c|}
\hline \multirow[b]{2}{*}{ mRS (0-2) } & \multicolumn{2}{|c|}{ Arcus arch type } & \multirow[b]{2}{*}{ p value ${ }^{*}$} \\
\hline & $\begin{array}{l}\text { Type } 1 \\
\text { N (\%) }\end{array}$ & $\begin{array}{l}\text { Type } 3 \\
\text { N (\%) }\end{array}$ & \\
\hline No & 39 (55.7) & 31 (44.3) & \multirow[b]{2}{*}{0.016} \\
\hline Yes & $30(78.9)$ & $8(21.1)$ & \\
\hline
\end{tabular}

the brachiocephalic trunk originated from the aortic arch to its peak. In this group, the aortic arch is divided into three types (7).

Wang et al. (11) investigated the characteristics of the aortic arch in an adult population in Chinese society. This study evaluated the arch structure of 2,370 patients using a thoracic computed tomography and revealed that type 1 arch structure was detected in 1,384 (58.4\%) patients, type 2 in 752 (31.7\%) patients, and type 3 in 234 (9.9\%) patients. The mean age of patients with type 1 arch structure was $55.4 \pm 12.3$ years, type 2 was $60.9 \pm 10.7$ years, and type 3 was $65.2 \pm 9.9$ years. Type 2 arch structure was more common in males than females $(p<0.01)(11)$. Some changes in the cardiovascular system as in many tissues were seen with aging. Smooth arteries and collagen rate increase, elastic tissue ratio decreases, and arteries stiffen and become curvier. Thus, the left ventricle of the heart, which tries to pump blood into the systemic circulation, puts more burden and may develop heart failure. In addition, the risk and frequency of chronic diseases, such as hypertension and type 2 diabetes, increase with age $(12,13)$. Thus, with increasing age, the arc structure deteriorates. Similarly, our study paralleled the increase in age with the increase in type 2 and type 3 aortic arch structures. 
The relatively low hemoglobin level in the elderly group of this study may suggest the presence of chronic additional diseases. In addition, smaller (5-F) DAC is used in this group during the endovascular procedure, which can be explained by the deterioration of age-related distal vascular structure $(p=0.021)$. A study conducted in our country evaluated 270 patients with cerebral angiography and revealed type 1 arch structure in 195 (72.2\%) patients, type 2 in 40 (14.8\%) patients, and type 3 in 35 (13\%) patients (9). Another study in our country by İnanç et al. (8) examined 288 patients with cerebral angiography and revealed 175 (61\%) patients with type 1, 99 (34\%) with type 2, and 14 (5\%) with type 3 arch structure. Unlike these studies, our study had a higher type 2 arch structure than the others due to the slightly low average age of our patients. A few studies investigated the relationship between the anatomical difference of the aortic arch and cerebrovascular disease. Patil et al. (14) argued that a relationship was found between the aortic anatomy and cerebrovascular disease, whereas Inanç et al. (8) revealed that the aortic arch and its branching features did not have a direct effect on the increased risk of cerebrovascular disease.

AIS is a clinical condition that is common among cerebrovascular diseases, caused by sudden inhibition of blood flow to some part of the brain for thromboembolic causes. If left untreated, it can result in serious injury and death. In the light of studies using new generation, thrombectomy and thromboaspiration devices in AIS, patients with proximal artery occlusion showed to provide higher rates of recanalization and reperfusion compared to IV r-tPA treatment (2). Many studies on "How can I achieve better clinical functional outcomes in endovascular treatment?" have been reported in the literature to date. For example, two major meta-analysis studies compared the effectiveness of direct aspiration and use of stent retriever in AIS treatment, which revealed an equally similar efficacy in achieving good clinical results in both studies $(5,15)$. Our study used direct aspiration and stent retriever techniques alone or together. Comparing patients with types 1 and 3 arch structures that result in successful recanalization ( $\geq \mathrm{mTICl} 2 \mathrm{~b}$ ), $\mathrm{mTICl} 2 \mathrm{~b}$ reperfusion was observed to be higher in patients with type 1 arc structure compared to type 3 , but without statistically significant differences. Bovine arch structure delayed the reperfusion time in patients with left anterior system occlusion. In addition, the use of stent retriever in patients with type 3 arch structure was less than the other types. Slater et al. (16) evaluated the endovascular treatment results in AIS of two important studies. According to the age distribution,
$\mathrm{TICl} 2 \mathrm{~b}-3$ reperfusion rates were higher in the elderly group (>70 years) compared to $\mathrm{TICl} 0$-2a reperfusion rates (16). The difference in our study was that patients with type 3 aortic arch structure have a worse prognosis compared to the third month of mRS. Here, patients with type 3 aortic arch structure also had advanced age and additional chronic problems.

Today, the quality and features of angiographic materials increase with the development of technology, which makes it possible to pass the complex arc structure simpler. Intravascular procedures are important for the diagnosis and treatment of the aortic type supra-aortic and cerebral vessels, and with types 1 to 3 , vascular catheterization and procedures will be difficult. The surgeon's experience and ability are other important factor. In addition, this allows the selection of the right technique and angiographic material, thereby shortening the time of the imaging and reducing the contrast agent to be used. Studies reported that brachial/radial access routes usage is easier than the femoral artery or direct carotid intervention for stent insertion into the carotid artery with complex aortic arch or interventions for intracranial arteries $(8,9,17,18,19)$.

\section{Study Limitations}

Very few studies reported on the aortic arch anatomy in the literature. Our study was performed retrospectively with file records. Therefore, some limitations are possible, such as having experienced and inexperienced surgeons and the use of different materials and techniques, thus, no prestandardized standardization. However, this retrospective study determined the total relationship between aortic arch classification and endovascular treatment success.

\section{Conclusion}

In conclusion, the complex arch structure was thought to have a negative effect on the success of endovascular treatment; however, this was not statistically significant. In addition, patients with the complex aortic arch structure are relatively older and the clinical prognosis after the procedure was found to be worse than younger patients with a simple aortic arch structure, which was statistically significant.

\section{Ethics}

Ethics Committee Approval: Ethics committee approval was obtained from the Gaziantep University Clinical Research Ethics Committee dated 12.25.2019 and 2019/479.

Informed Consent: Patient consent was obtained.

Peer-review: Externally and internally peer-reviewed. 


\section{Authorship Contributions}

Surgical and Medical Practices: M.Ç., N.Ş., A.E., Y.I., S.G., Concept: M.C.., Design: M.C.., Data Collection or Processing: M.C.., N.S., A.E., Analysis or Interpretation: M.C.., N.S., Literature Search: M.Ç., Writing: M.Ç., N.Ş.
Conflict of Interest: No conflict of interest was declared by the authors.

Financial Disclosure: The authors declared that this study received no financial support.

\section{REFERENCES}

1. Conway AM, Nguyen Tran NT, Qato K, et al. Complexity of aortic arch anatomy affects the outcomes of transcarotid artery revascularization versus transfemoral carotid artery stenting. Ann Vasc Surg 2020;67:78-89.

2. Powers WJ, Derdeyn CP, Biller J, et al. 2015 American Heart Association/American Stroke Association Focused Update of the 2013 Guidelines for the Early Management of Patients With Acute Ischemic Stroke Regarding Endovascular Treatment: A Guideline for Healthcare Professionals From the American Heart Association/ American Stroke Association. Stroke 2015;46:3020-3035.

3. Goyal M, Menon BK, van Zwam WH, et al. Endovascular thrombectomy after large-vessel ischaemic stroke: a meta-analysis of individual patient data from five randomised trials. Lancet 2016;387:1723-1731.

4. Dargazanli C, Consoli A, Barral M, et al. Impact of modified TICI 3 versus modified $\mathrm{TICI} 2 \mathrm{~b}$ reperfusion score to predict good outcome following endovascular therapy. AJNR Am J Neuroradiol 2017;38:9096.

5. Primiani $\mathrm{CT}$, Vicente $\mathrm{AC}$, Brannick MT, et al. Direct aspiration versus stent retriever thrombectomy for acute stroke: a systematic review and meta-analysis in 9127 patients. J Stroke Cerebrovasc Dis 2019;28:1329-1337.

6. Madjidyar J, Pineda Vidal L, Larsen $\mathrm{N}$, Jansen 0 . Influence of thrombus composition on thrombectomy: ADAPT vs. balloon guide catheter and stent retriever in a flow model. Rofo 2020;192:257263.

7. Madhwal S, Rajagopal V, Bhatt DL, Bajzer CT, Whitlow P, Kapadia SR. Predictors of difficult carotid stenting as determined by aortic arch angiography. J Invasive Cardiol 2008;20:200-204.

8. İnanç $\mathrm{Y}$, İnanç $\mathrm{Y}, \mathrm{Ay} \mathrm{H}$. The effect of demographic features on aortic arch anatomy and its role in the etiology of cerebrovascular disease. Neuropsychiatr Dis Treat 2017;14:29-35.
9. Ergun O, Tatar IG, Birgi E, et al. Angiographic evaluation of branching pattern and anatomy of the aortic arch. Turk Kardiyol Dern Ars 2015;43:219-226.

10. McElhinney DB, Clark BJ 3rd, Weinberg PM, et al. Association of chromosome 22q11 deletion with isolated anomalies of aortic arch laterality and branching. J Am Coll Cardiol 2001;37:2114-2119.

11. Wang L, Zhang J, Xin S. Morphologic features of the aortic arch and its branches in the adult Chinese population. J Vasc Surg 2016;64:1602-1608.e1.

12. Ferrari AU, Radaelli A, Centola M. Invited review: aging and the cardiovascular system. J Appl Physiol (1985) 2003;95:2591-2597.

13. Altuntaş Y. Approach toward diabetes treatment in the elderly. Sisli Etfal Hastan Tip Bul 2019;53:96-102.

14. Patil ST, Meshram MM, Kamdi NY, Kasote AP, Parchand MP. Study on branching pattern of aortic arch in Indian. Anat Cell Biol 2012;45:203-206

15. Hsieh KL, Chuang KI, Weng HH, Cheng SJ, Chiang Y, Chen CY. first-line a direct aspiration first-pass technique vs. first-line stent retriever for acute ischemic stroke therapy: a meta-analysis. Front Neurol 2018;9:801.

16. Slater LA, Coutinho JM, Gralla J, et al. TICI and Age: What's the Score? AJNR Am J Neuroradiol 2016;37:838-843.

17. Demertzis S, Hurni S, Stalder M, Gahl B, Herrmann G, Van den Berg J. Aortic arch morphometry in living humans. J Anat 2010;217:588596

18. Shaw JA, Gravereaux EC, Eisenhauer AC. Carotid stenting in the bovine arch. Catheter Cardiovasc Interv 2003;60:566-569.

19. Roche A, Griffin E, Looby S, et al. Direct carotid puncture for endovascular thrombectomy in acute ischemic stroke. J Neurointerv Surg 2019;11:647-652. 